\title{
Impact of good practices of handling training on beef cattle welfare and stockpeople attitudes and behaviors
}

\author{
Maria C. Ceballos $^{\mathrm{a}, \mathrm{b}}$, Aline C. Sant'Anna ${ }^{\mathrm{a}, \mathrm{c}}$, Xavier Boivin ${ }^{\mathrm{d}}$, Franciely de Oliveira Costa ${ }^{\mathrm{a}, \mathrm{b}}$, \\ Monique V. de L. Carvalhal ${ }^{\mathrm{a}, \mathrm{b}}$, Mateus J.R. Paranhos da Costa ${ }^{\mathrm{a}, \mathrm{e}, *}$ \\ a Grupo de Estudos e Pesquisas em Etologia e Ecologia Animal, Departamento de Zootecnia, Faculdade de Ciências Agrárias e Veterinárias, Universidade Estadual Paulista, \\ Jaboticabal, SP 14.884-900, Brazil \\ b Programa de Pós-Graduação em Zootecnia, Faculdade de Ciências Agrárias e Veterinárias, Universidade Estadual Paulista, Jaboticabal, SP 14.884-900, Brazil \\ ${ }^{\mathrm{c}}$ Departamento de Zoologia, Instituto de Ciências Biológicas, Universidade Federal de Juiz de Fora, Juiz de Fora, MG 36.036-330, Brazil \\ d Université Clermont Auvergne, INRA, VetAgro Sup, UMR Herbivores, F-63122 Saint-Genès-Champanelle, France

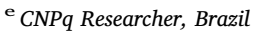

\section{A R T I C L E I N F O}

\section{Keywords:}

Human-animal interaction

Zebu cattle

Quality of handling

Working day time

\begin{abstract}
A B S T R A C T
The aims of this study were to evaluate the potential impacts of training in good practices of cattle handling on stockpeople's attitudes and behavior, and on cattle welfare, in Brazilian beef farms. Additionally, we aimed to investigate whether the quality of cattle handling deteriorates as the working day progresses. The study was conducted on 24 commercial beef cattle farms (located in Northeastern Pará State, Brazil), which were classified into three groups with different levels of training: Regularly trained (TRAINED-R, $n=9$ ), Occasionally trained (TRAINED-O, $n=9$ ) and Never trained (NON-TRAINED, $n=6$ ). A total of 150 stockpeople working on these farms were categorized according to the level of training received: i) Trained (TS, $n=43$ ), those who attended formal handling skills training; ii) Non-trained, but had close contact with a trained stockperson (CTS, $n=62$ ), and iii) Non-trained, and had no contact with a trained stockperson (NT, $n=45)$. On each farm, indicators of quality of handling (including animal and stockpeople behavior, and stockpeople attitudes) were measured on one workday, during the vaccination handling procedures of approximately $236 \pm 65$ (mean \pm SD) heads of cattle per farm. We observed that NON-TRAINED farms had the poorest quality of handling, as well as more undesirable animal behaviors during handling $(P<0.05)$, when compared with the other farm categories (TRAINED-R, TRAINED-O). Stockpeople attitudes and behaviors varied according to their degree of training in good practices of beef cattle handling $(P<0.05)$. People who participated in a formal training course (TS) had the highest positive and the lowest negative behavior and attitude scores, compared with people in the other groups (CTS and NT). We observed an effect of the progression of the workday $(P<0.05)$ only on NONTRAINED farms, where handling became worse over time. Our results support the hypothesis that training stockpeople in good cattle handling practices leads to better attitudes and behavior toward cattle. Thus, training stockpeople can be an effective and practical strategy to promote positive human-animal interactions on beef cattle farms, improving the quality of life of both animals and workers.
\end{abstract}

\section{Introduction}

It is well known that stockpeople's attitude towards their animals is directly associated with their behavior during handling and that rough practices can negatively affect animal welfare, increasing animals' fear towards humans (Hemsworth, 2007; Hemsworth and Coleman, 2011). On the other hand, when the animals experience positive interactions with humans, they become less fearful, which, in turn, facilitates handling (Schmied et al., 2010; Probst et al., 2012).

In most cases, stockpeople's negative attitudes and behaviors towards animals cannot be characterized as intentional cruelty (Hemsworth, 2007). In the daily routine of livestock production, where handling practices are usually learned from working "on the job", it is very common for stockpeople to believe that their behaviors are harmless to the animals (Hemsworth, 2007). Many farmers consider beef cattle to be dangerous and difficult to handle (Boivin et al., 2007),

\footnotetext{
* Corresponding author at: Grupo de Estudos e Pesquisas em Etologia e Ecologia Animal, Departamento de Zootecnia, Faculdade de Ciências Agrárias e Veterinárias, Universidade Estadual Paulista, Jaboticabal, SP 14.884-900, Brazil.

E-mail address: mpcosta@fcav.unesp.br (M.J.R. Paranhos da Costa).
} 
which may increase their stress during handling and underlie their difficulties on the job. Additionally, a heavy workload and the risk of accidents have been identified as stress-inducing job characteristics of stockpeople on cattle farms (Douphrate et al., 2013; Lindahl et al., 2013; Menger et al., 2016). Job stress is defined as "the harmful physical and emotional responses that occur when the requirements of the job do not match the capabilities, resources, or needs of the worker" (NIOSH, 1999), and farming is thought to be among the jobs with the highest levels of job stress. Stress influences stockpeople's decisionmaking, effectively lowering their willingness to adopt better handling practices (Burnett, 2014). However, to the best of our knowledge, few studies have investigated the long-term implications of handling involving repetitive, dangerous and exhaustive tasks (e.g., handling large herds of beef cattle). In a completely different research area (medical nursing), it has been proposed that compassion discomfort, compassion stress, and finally compassion fatigue, may lead to poor quality of care (Coetze and Klopper, 2010). This research could be a source of inspiration for understanding stockpeople behavior towards farm animals. Thus, complex factors determining human behavior including beliefs, job satisfaction (Boivin et al., 2003; Coleman and Hemsworth, 2014) and workload should be investigated further.

Stockpeople behavior during livestock handling can be improved by carefully selecting personnel and developing training programs designed to reduce animal stress during handling (Boivin et al., 2007). Thus, training programs designed to change stockperson attitudes and behaviors present a good opportunity to improve human-animal interactions in livestock industries (Hemsworth and Coleman, 2011) by using behavioral modification rather than just skill transfer (Coleman and Hemsworth, 2014). Indeed, a few studies conducted with dairy cattle and pigs have shown that cognitive/behavioral interventions can improve workers' attitudes and consequently their behavior (Hemsworth et al., 1994; Coleman et al., 2000; Hemsworth et al., 2002). However, these authors have emphasized that training efficacy depends on the interactions between all trained and non-trained stockpeople on the same farm, and on whether or not a common culture towards animal handling can be developed (Coleman and Hemsworth, 2014).

Thus, handling skills training programs are essential to improve animal handling in livestock production. This is especially true in Brazil, which houses the world's largest commercial cattle herd (215.2 million cattle heads; IBGE, 2016) and is among the world's major beef exporters (USDA, 2018). There is also a growing demand for training among Brazilian farmers themselves, who are adopting productive precepts aiming to meet sustainable, social and environmental dimensions in cattle production. Thus, offering stockpeople continued education in good handling practices and welfare may help them reach this goal (Zuin et al., 2014). Although training programs for beef cattle handling already exist (Zuin et al., 2014), no studies to date (in Brazil or elsewhere) have investigated the effects of these programs on stockperson attitudes and behaviors. Investigating the efficacy of training in beef production is interesting because, in contrast to dairy cattle management, there is no daily handling of cattle for milking, and there are therefore fewer possibilities for the trainees to practice after their training sessions.

Thus, the aims of this study were to evaluate the impacts of cattle handling skills training on stockpeople's attitudes and behaviors, and on cattle welfare, in Brazilian beef farms. We compared farms where all stockpeople were trained to farms where only some stockpeople were trained and farms where no one was trained. Finally, we also investigated whether the quality of cattle handling deteriorates over time as the workday progresses. We hypothesized that trained stockpeople would have better attitudes and behaviors toward cattle and would handle them in a consistent way throughout the workday.

\section{Materials and methods}

This research was carried out according to Brazilian legislation and was approved by the Committee for the Ethical Use of Animals from the Faculty of Agricultural and Veterinary Sciences of São Paulo State University (Protocol n. 014198/14), Jaboticabal, SP, Brazil.

\subsection{Farms, stockpeople, training strategies and animals}

The study was conducted on 24 commercial beef cattle farms located in Northeastern Pará State, Brazil. Farms fell into three groups defined according to their access to cattle handling training: $i$ ) Farms with systematic training programs (TRAINED-R, $n=9$ ), where an expert in applied ethology and animal welfare trained and advised the permanent employees about good practices of beef cattle handling for more than one year, through periodic visits (at least once every 6 months); ii) Farms with occasional training (TRAINED-O, $n=9$ ), where at least one (but not all) of the permanent employees received formal training on good practices of beef cattle handling; and iii) Non trained farms (NON-TRAINED, $n=6$ ), where none of the workers received any training on good practices of beef cattle handling. All farms also employed day laborers who received no training.

A total of 150 stockpeople (all men) were categorized according to their previous access to information or training on good practices of cattle handling, as follows: i) Trained stockpeople (TS, $n=43$ ), who had attended formal training; ii) Non-trained stockpeople (CTS, $n=62$ ), who had not attended any formal training but were part of a team where at least one colleague was trained (which may give them occasional access to information about good handling practices); and iii) Non-trained stockpeople (NT, $n=45$ ), who did not attend any formal training nor had any contact with a trained stockperson on their farm. The distributions of these categories within each farm class are presented in Table 1.

In this study, formal training activities in "good practices of beef cattle handling" were part of an existing training program (performed not only during this study), which included theoretical lectures and practical activities designed to encourage stockpeople to improve their interactions with cattle in order to minimize animal physiological stress. The training emphasized the importance of using knowledge about cattle behavior to implement good practices of cattle handling (and presented a series of recommendations for handling), and addressed the implications of animal welfare and human-animal interactions on cattle production. All this information was derived from guidelines developed by our research group in Brazil, addressing beef cattle vaccination procedures (Paranhos da Costa et al., 2006) among other subjects (e.g. calf handling at birth and weaning, identification, cattle loading and transport). Throughout the training, instructors emphasized that aversive handling (frequent or not) has a negative influence on cattle behavior, making animals fearful of humans. The course was offered over three continuous days and included a practical portion on the last day.

The maximum number of heads evaluated per farm was 250 , and an average of $236 \pm 65$ (mean \pm SD) animals were assessed per day at each of the 24 farms, for a total of 5,659 animals. All 24 farms kept

\section{Table 1}

Distribution of the type of stockpeople (TS $=$ Trained; CTS $=$ Non-trained, but had close contact with a trained stockperson; NT $=$ Non-trained) within each group of farms: farms with regular training = TRAINED-R, farms with some training sections $=$ TRAINED-O and farms without any type of training $=$ NONTRAINED.

\begin{tabular}{llll}
\hline Type of stockpeople & TRAINED-R & TRAINED-O & NON-TRAINED \\
\hline TS & $69.8 \%(n=30)$ & $30.2 \%(n=13)$ & 0 \\
CTS & $37.1 \%(n=23)$ & $46.8 \%(n=29)$ & $16.1 \%(n=10)$ \\
NT & $15.6 \%(n=7)$ & $17.8 \%(n=8)$ & $66.7 \%(n=30)$ \\
\hline
\end{tabular}


cattle on tropical pastures with mineral supplementation. With some variations across farms, the working routine of most consisted of stockpeople on horseback driving the cattle from the pastures to the corral, where they were held in the holding yards for a variable period of time. Then, they were driven to the forcing yard in smaller groups, and from there, into the single-file race. Stockpeople (on foot) stimulated the animals individually to walk along the single-file race and enter the squeeze chute. The animals were classified in three groups, according to breed and breed-type: $1=$ Nellore calves, $2=$ Nellore cows and heifers, $3=$ Predominantly crossbred adult bulls. These groups of animals were represented in all categories of farm training.

\subsection{Assessing stockpeople and animal behavior during handling}

All assessments were carried out during one day of subcutaneous foot-and-mouth vaccination procedures at each corral. At each farm, three trained observers recorded stockpeople and animal behaviors during handling in three corral sections (one observer in each section): the crowding pen, the working chute and the squeeze chute. Animals and stockpeople were observed continuously during all the handling procedures (each animal was assessed continuously from the time it entered the crowding pen until it exited the squeeze chute). The recording rule was 'continuous' and the sampling rule was 'behavior sampling' (the observer watched a whole group of individuals and recorded each occurrence of specific behaviors, as well as which individuals were involved, according to Martin and Bateson, 2007). While observers were not aware of individual stockpeople's access to information or training, they did know which farms had systematic training.

\subsubsection{Assessment of cattle behaviors and accidents}

Cattle behaviors and accidents were assessed in the crowding pen and working chute during handling for the vaccination procedure. The following behavioral categories were recorded (adapted from Macedo et al., 2011): a) jumping - the animal pushed itself off the surface and kept its front legs in the air; b) lying down - the animal lay down smoothly, maintaining sternal recumbence; c) return/balking - the stockperson tried to drive the animal in a particular direction, but it moved backwards or avoided entering the working or squeeze chute; d) attack - the animal showed aggressive behavior toward the stockperson (head front down, moving toward the human, sometimes blowing air or charging); e) falls -any part of the animal's body (other than the hooves), touched the ground as a result of a sudden movement; f) bump on the facilities - the animal hit or stumbled on any structural part of the facilities, and; g) being trampled by another animal in the chute - a lying or keeling animal was trampled by another animal during handling. The frequencies of all these categories were added together to compose a new indicator of cattle behavior, 'undesirable behaviors and accidents' (UBA).

\subsubsection{Assessment of stockpeople behaviors and attitudes}

The quality of handling was assessed by recording the behaviors of each stockperson, individually, during handling procedures in the crowding pen, working chute and squeeze chute. The following behavioral categories were recorded in the crowding pen and working chute: correct use of handling flag, when the handler applied the concept of flight zone to move the animals without physical contact (see Grandin and Deesign (2008) and Grandin (2017) for a description of handling flag use and flight zone); positive tactile interactions (adapted from Waiblinger et al., 2002), all occurrences of gentle touch on the animal's body; negative tactile interactions (adapted from Waiblinger et al., 2002), occurrences of hitting the gate against the animal, hitting and prodding the animals with the hands or any implement, such as a wooden stick or electric prod (positive and negative tactile interactions are described in Table 2); positive vocalization (adapted from Waiblinger et al., 2002), the use of low tone voice commands and soft whistles; negative vocalization and other acoustic sounds (adapted from Waiblinger et al., 2002), the frequency of shouts, loud whistles, and noises when hitting any tool on the corral structure; negative contact with the animal's tail (i.e., twisting it to stimulate the animal to move). We then combined the frequencies of these behaviors to create two new variables of stockpeople handling quality: Positive behaviors $(P B)=$ sum of the frequencies for correct use of handling flag, positive tactile interactions, and positive vocalization; and Negative behaviors (NB): sum of the frequencies for negative tactile interactions, negative vocalization and other acoustic sounds, and negative contacts with the animal's tail.

Positive and negative behaviors (PB and NB) were also recorded in the squeeze chute, where additional handling actions were also recorded, in three different situations: 1) when the animals entered the squeeze chute, the observer assessed the operation of the front gate of the squeeze chute (GATE) and assigned one of two scores: (1) correct $=$ the gate was opened just to stimulate the animal to enter, was closed immediately before it entered, the animal was restrained with the head bail, and the gate remained closed during the vaccination procedure, and (2) wrong $=$ the door was kept open after restraining the animal throughout the vaccination process. This last door position was considered wrong because it favored the animal's escape during the vaccination process, thus increasing the risk of accidents. The relative frequency of score 2 on each farm was used in the statistical analyses.

The second situation was when the animal was restrained with the head bail. Here, we recorded the frequency of a stockperson's attempts to restrain an animal with the head bail (RESTRAIN), and the speed and force used to do so (REST.HB). For this situation, we assigned three different scores: $(1)=$ when the head bail was operated slowly to approach the animal's neck without hitting it, (2) = when the head bail was operated quickly, but without hitting the animal's neck, and (3) = when the head bail was operated with quick and vigorous movements, hitting the animal's body with force. The statistical analyses of RESTRAIN were conducted considering the relative frequency at which the stockperson attempted to restrain an animal three or more times; and for REST-HB we used the relative frequencies of the worst scores (3) per farm.

Finally, the third situation was during vaccination. We recorded (i) failures during vaccination (F.VACCINATION) by measuring how many needle insertions were needed to deliver one dose of vaccine; (ii) whether an incorrect injection site was used (SITE; e.g. neck shoulder, hump, ribs, rump or base of the tail) and the relative frequency of animals that received the injection in a body part other than the neck; (iii) poor quality of subcutaneous injection (PQI), which included two possible scores: $(1)=$ when the handler pulls the animal's skin and inserts the needle in the skin fold (recommended procedure for subcutaneous injection), and (2) = when the needle insertion is performed without pulling the skin; and (iv) attempt to escape (ESCAPE), or the number of escape attempts during handling in the squeeze chute (measured by the number of times the animal put their head or body out of the lateral window or gate of the squeeze chute). Dependent variables were the relative frequencies (within each farm) of failures in vaccination (defined as two or more needle insertions to deliver one dose of vaccine), animals vaccinated in a body part other than the neck, score 2 of PQI, and animals attempting to escape.

Between one week and one month after assessing the quality of cattle handling, each stockperson participated in a structured interview that aimed to assess their attitudes towards cattle, work satisfaction and perceptions of handling practices. The interview consisted of 26 items (adapted from Boivin et al., 2007) divided into three parts, as presented in Table 3. The first part, addressing attitudes toward cattle, comprised 11-items; the second part (also with 11-items) focused on the stockperson's attitudes toward handling practices; and the third part (with 5 items) was related to work satisfaction. Before starting the interview, we informed all stockpeople that their opinion about working with cattle would be a useful addition to our study. As not all stockpeople 
Table 2

Definitions of tactile interactions with the animals made by the stockperson.

\begin{tabular}{|c|c|}
\hline Category & Definition \\
\hline Touch & $\begin{array}{l}\text { Act of softly touching the animal with hands and fingers or with any kind of tool like flag, stick, stinger, etc. This contact is not violent and } \\
\text { does not cause any kind of injury to the animal. }\end{array}$ \\
\hline Hitting and prodding the animal & $\begin{array}{l}\text { Act of brusquely hitting the animal with hands, feet or any kind of tool like flag, stick, stinger, etc. This contact is violent and may cause } \\
\text { injury to the animal. }\end{array}$ \\
\hline Hitting the gate against the animal & Brusquely hitting the animals with a gate (corral structure with the function of close or split environments). \\
\hline Use of electric prod & Act of touching the animal with a prod that promotes electric discharges. \\
\hline
\end{tabular}

were able to read the questionnaire, interviewers read each question without any comment and recorded their responses in categories, from 1 (fully disagree) to 5 (fully agree).

Because stockpeople were informed that the observers were there to evaluate cattle behavior, they were partially aware of the study's purpose. Participation in the interviews was voluntary and did not involve physical or mental risks to the workers. They were free to withdraw from the interview and research study at any time and were informed about this before the interview. At the end of the study, all the interviewed stockpeople were informed about the full purpose of the study, detailing that all data would be processed and treated anonymously during data analyses, interpretation and publication.

\subsection{Statistical analyses}

We first applied a multivariate factor analysis to the questionnaire data. For this we extracted main factors through a Principal Component Analysis (PCA) with varimax rotation using the Statistica software
(Statsoft, version 7). Data input for the PCA was determined by summing up all answers to each question (number of answers ranging from 1 to 5 per question). Factor analyses of the 26 items generated two components that represented positive and negative stockpeople attitudes. These components contained 16 and 10 questions, respectively, with loadings above 0.5 (Table 3). Based on the factor analysis results, each stockperson's responses were summed to produce composite scores for the 16 positive and 10 negative attitude questions (adapted from Breuer et al., 2000).

For the subsequent statistical analyses, two sets of data were created, one considering data with stockpeople as the experimental unit and the other with farm as the experimental unit.

\subsubsection{Effects of stockpeople training groups on stockpeople's individual attitudes and behaviors}

To evaluate the effects of stockpeople training in good practices of beef cattle handling on their attitudes (positive and negative), linear mixed models were used, via PROC MIXED of SAS (version 9.3, SAS

Table 3

Percentages of responses (from 1 - fully disagree to 5 - fully agree) characterizing stockpeople's $(n=150)$ attitudes toward cattle, handling behavior and work satisfaction; and loadings of the two factors estimated by the factor analysis for questionnaire data.

\begin{tabular}{|c|c|c|c|c|c|c|c|}
\hline Attitudes & 1. Fully disagree & 2 & 3 & 4 & 5. Fully agree & Loadings Factor 1 & Loadings Factor 2 \\
\hline \multicolumn{8}{|l|}{ Toward cattle } \\
\hline Cattle have good memory & 5 & 0 & 6 & 12 & 78 & $0.992^{*}$ & 0.102 \\
\hline Recognize the stockperson & 5 & 1 & 4 & 7 & 83 & $0.994^{*}$ & 0.083 \\
\hline Have learning capacity & 1 & 1 & 4 & 6 & 89 & $0.992^{*}$ & 0.114 \\
\hline Easily scares & 2 & 1 & 13 & 3 & 81 & $0.992^{*}$ & 0.084 \\
\hline Are afraid of unfamiliar people & 6 & 1 & 14 & 10 & 69 & $0.993^{*}$ & 0.074 \\
\hline Are sensitive to pain & 0 & 0 & 0 & 2 & 98 & $0.991 *$ & 0.096 \\
\hline Can suffer and feel pain when hit & 1 & 0 & 1 & 2 & 97 & $0.992^{*}$ & 0.090 \\
\hline Flees in fear & 2 & 1 & 3 & 9 & 84 & $0.989 *$ & 0.123 \\
\hline Are stubborn and hard to handle & 29 & 6 & 43 & 9 & 12 & -0.172 & $-0.592 *$ \\
\hline Are afraid of familiar people & 64 & 6 & 19 & 3 & 8 & -0.177 & $-0.979^{*}$ \\
\hline Are dangerous & 34 & 1 & 29 & 9 & 27 & 0.401 & $-0.809^{*}$ \\
\hline \multicolumn{8}{|l|}{ Toward handling behavior } \\
\hline You need to hit the cattle to handle it & 66 & 12 & 18 & 3 & 1 & -0.340 & $-0.926^{*}$ \\
\hline Iron stick is useful & 77 & 3 & 9 & 6 & 5 & -0.200 & $-0.941^{*}$ \\
\hline Handling flag disrupts handling & 81 & 3 & 10 & 1 & 5 & -0.184 & $-0.956^{*}$ \\
\hline You need to jump and wave hands & 57 & 5 & 14 & 8 & 16 & -0.037 & $-0.978^{*}$ \\
\hline You need to poke with a stick to make them enter into the squeeze chute & 36 & 8 & 34 & 8 & 14 & -0.149 & $-0.832^{*}$ \\
\hline You need to raise your voice to be obeyed & 73 & 9 & 14 & 2 & 2 & -0.271 & $-0.939 *$ \\
\hline You need to apply a lot of effort & 50 & 10 & 13 & 3 & 24 & 0.183 & $-0.949^{*}$ \\
\hline You talk softly to be obeyed & 0 & 0 & 5 & 6 & 88 & $0.992^{*}$ & 0.121 \\
\hline Handling flag is useful & 5 & 0 & 3 & 10 & 82 & $0.991 *$ & 0.094 \\
\hline You need to use soft touch to be obeyed & 6 & 4 & 30 & 10 & 49 & $0.881^{*}$ & 0.082 \\
\hline Facilities influence the handling & 3 & 1 & 1 & 3 & 93 & $0.991 *$ & 0.080 \\
\hline \multicolumn{8}{|l|}{ Work satisfaction } \\
\hline You want to work for a long time & 10 & 2 & 14 & 10 & 64 & $0.997^{*}$ & 0.026 \\
\hline Like working with cattle & 1 & 1 & 8 & 13 & 77 & $0.985^{*}$ & 0.159 \\
\hline Training is important & 1 & 0 & 0 & 12 & 87 & $0.984^{*}$ & 0.135 \\
\hline If you had the opportunity, you would participate in training & 1 & 1 & 2 & 4 & 92 & $0.991 *$ & 0.100 \\
\hline Eigenvalues & & & & & & 16.752 & 7.539 \\
\hline$\%$ Total variance & & & & & & 64.4 & 29.0 \\
\hline
\end{tabular}

Loadings with * represent the questions with the most positive contributions on factor 1, representing the stockpeople's positive attitudes; and the most negative contributions on factor 2 , representing the stockpeople's negative attitudes. 
Institute Inc., Cary, NC, USA), with positive and negative attitudes as response variables, stockperson training category (TS, CTS and NT) as a fixed effect, and farm as a random effect. The normal distribution of the data was visually tested by plotting raw and standardized residuals.

To assess the effects of access to training on stockpeople's positive and negative behaviors, generalized linear mixed models were fitted with lognormal distributions of the response variables (PB and NB) using PROC GLIMMIX in SAS. Models included the fixed effect of stockperson training category (TS, CTS and NT), and farm as a random effect. Raw and standardized residuals were plotted, and their distributions were examined to determine the lognormal distribution of the response variables.

In all analyses, the post hoc Tukey test was applied for means comparisons and significance was set at $P<0.05$. We also tested stockpeople characteristics such as age, time working with cattle, and time spent working in the assessed farm. Because we observed no significant effects $(P>0.05)$ for these variables, we excluded them from the final models.

\subsubsection{Effects of farm training groups on stockpeople quality of handling}

The response variables in the farm dataset were: operation of the front gate of the squeeze chute (GATE), stockperson's attempts to restrain each animal (RESTRAIN), speed and force used to restrain the animal (REST.HB), failures in vaccination attempts (F.VACCINATION), incorrect injection site (SITE), poor quality of subcutaneous injection (PQI), ESCAPE and undesirable behaviors and accidents (UBA), as well as farm positive behaviors ( $F P B$, characterized by the sum of $\mathrm{PB}$ for all stockpeople within each farm during the entire handling section); and farm negative behaviors (FNB, defined by the sum of NB for all stockpeople within each farm). Use of electric prod was not included in these analyses, because only three farms in the NON-TRAINED group used it. Raw and standardized residuals were plotted, and their distributions were examined to determine the distributions of the dependent variables: FPB, FNB, RESTRAIN, F.VACCINATION and ESCAPE followed lognormal distributions; REST.HB and UBA, Poisson distribution; and GATE, SITE, PQI, normal distributions.

The effect of farm training categories on farm handling variables (FPB, FNB, GATE, RESTRAIN, REST.HB, F.VACCINATION, SITE and PQI) was assessed. Models included category of farm (TRAINED-R, TRAINED-O and NON-TRAINED) as the fixed effect, and handling speed (number of animals per minute) as a covariate with linear effects. The effects of number of stockpeople at each handling session and breedtype of animals were tested for each response variable, and were not included in the final models because no significant effects were found $(P>0.05)$. The PROC MIXED in SAS was used for variables with normal distribution (GATE, SITE, and PQI) and PROC GLIMMIX for non-normal variables, fitting generalized linear mixed models and specifying the respective distributions of the response variables.

To test the relationship between farm training category with ESCAPE and UBA, generalized linear mixed models were fitted, using PROC GLIMMIX in SAS, with the fixed effects of farm category (TRAINED-R, TRAINED-O and NON-TRAINED), breed-type of animals (1-Nellore calves, 2-Nellore cows and heifers, and 3-Predominantly crossbred adult males) and their interaction. Handling speed (number of animals per minute) was included as a covariate with linear effects.

\subsubsection{Effect of the time elapsed within a workday on the quality of handling} and cattle behavior

Finally, we tested the hypothesis that quality of handling deteriorates as time elapses within a workday. For this, we conducted a simple regression analysis for each farm training category, using handling quality and cattle behavior as dependent variables (FPB, FNB and UBA) and the effect of time of handling (every 15 min of work). To do this, we quantified the occurrences of FPB, FNB and UBA, independently, every 15 minutes, until the end of the workday on each farm. For these analyses, the response variables were log-transformed (on a $\log _{\mathrm{e}}$ basis) to obtain normal distributions, and then the PROC GLM in SAS was used.

\section{Results}

\subsection{Effects of training groups on stockpeople's individual attitudes and behaviors}

The questionnaire data generated two main factors explaining $93.4 \%$ of the variance in the data set (Table 3). In the first factor (covering $64.4 \%$ of the variance), 16 questions had positive loadings above 0.5 , and all of them were characterized as indicative of stockpeople's positive attitudes. In the second factor (explaining $29.0 \%$ of the variance), 10 questions had negative loadings above 0.5 , and these questions were characterized as indicative of negative attitudes. Most stockpeople showed high agreement with the questions indicating positive attitudes, and disagreement with the questions indicating negative attitudes toward cattle (see Table 3).

Each stockperson's responses to positive and negative attitude questions were summed to produce a composite measure (adapted from Breuer et al., 2000). The average positive attitude score for all stockpeople was $74.0 \pm 4.5$ (mean $\pm \mathrm{SD}$; range, 56 to 80 ), and the average negative attitude score was $21.4 \pm 6.7$ (range, 10-41). The percentage of stockpeople showing above average positive attitude scores was higher for the trained group $(65.5,61.2$ and $28.1 \%$, for TS, CTS and NT, respectively) and, as expected, the percentage of stockpeople with above average negative attitude scores was lower for the trained group (27.3, 59.7 and $68.8 \%$ for TS, CTS and NT, respectively).

There was a significant difference between training groups in terms of positive and negative attitude scores $\left(\mathrm{F}_{2}, 131=4.50\right.$, and $\mathrm{F}_{2}$, $131=16.30, P<0.01)$ : trained stockpeople had significantly higher $(P<0.01)$ positive attitudes (mean $\pm \mathrm{SD})(\mathrm{TS}=75.41 \pm 0.71)$ than non-trained stockpeople (NT $=72.40 \pm 0.72$ ), and there was no difference between these two groups and the group of stockpeople who had occasional access to information (CTS $=74.14 \pm 0.60$ ) $(P>0.05)$. On the other hand, negative attitudes were significantly higher for the non-trained group ( $\mathrm{NT}=25.45 \pm 0.99$ ), followed by the occasionally informed group (CTS $=21.26 \pm 0.80$ ), and finally by the trained group (TS $=17.54 \pm 0.97)$, and all groups differed significantly among each other $(P<0.01)$.

Significant differences between stockpeople training groups were found for both stockpeople positive behaviors (PB) and negative behaviors (NB) $\left(F_{2}, 135=7.32, P<0.01\right.$ and $F_{2}, 132=3.38, P<0.05$, respectively). As expected, trained stockpeople showed more $\mathrm{PB}$ and less NB than non-trained stockpeople, but did not differ from occasionally informed stockpeople (Fig. 1).

\subsection{Effects of farm training groups on stockpeople quality of handling}

A significant effect of the farm training category was found on farm positive behaviors (FPB, $\mathrm{F}_{2,20}=3.65, P=0.045$ ), speed and force used to restrain the animal (REST.HB, $F_{2,17}=65.16, P<0.001$ ), and poor quality of subcutaneous injection (PQI, $F_{2,20}=7.68, P=0.003$ ) (Table 4). Trained farms had higher FPB and lower REST.HB than NONTRAINED farms (Table 4). There were higher PQI values for the NONTRAINED group, with $100 \%$ of those farms vaccinating animals in the wrong way, followed by the TRAINED-O and TRAINED-R groups, which did not differ from each other ( 48.25 and $22.78 \%$, respectively). No significant effects of farm training category were found for farm negative behaviors (FNB), operation of the front gate of the squeeze chute (GATE), stockperson's attempts to restrain the animal (RESTRAIN), failures in vaccination attempts (F.VACCINATION), incorrect injection site (SITE), or ESCAPE $(P>0.05)$. Nevertheless, an interesting numeric difference was found for ESCAPE, with approximately 6 times more escape attempts from the squeeze chute for NON-TRAINED $(1.41 \pm 0.75)$ versus TRAINED-R farms $(0.24 \pm 0.61)$. 

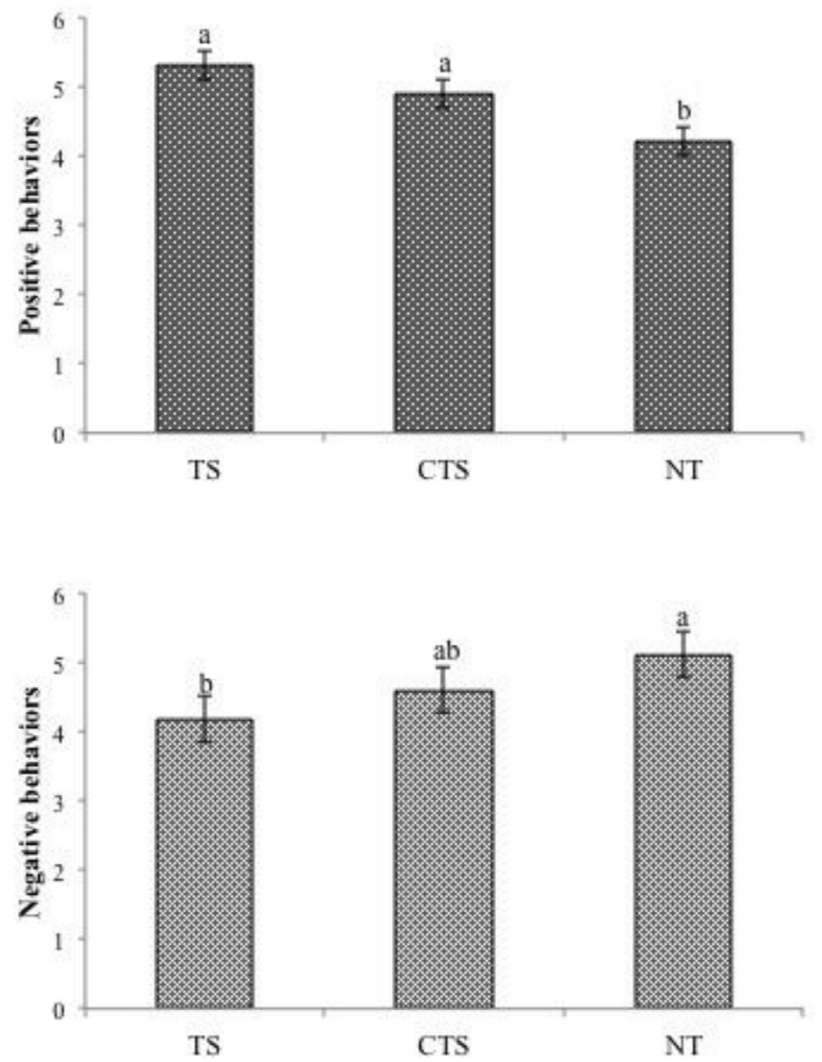

(b)

Fig. 1. Adjusted means ( \pm SE) of positive (a) and negative behaviors (b) according to stockpeople's access to good practices of beef cattle handling information or training (Trained stockperson $=$ TS, Non-trained but had close contact with trained stockperson $=$ CTS and Non-trained stockperson $=\mathrm{NT}$ ). Numbers with same case letters are not statistically different $(P>0.05)$, according to post-hoc Tukey tests.

Table 4

Adjusted means ( \pm SE) of the effect of each farm training group (farm training group $=$ TRAINED-R, farms with at least one employer trained in an official training course $=$ TRAINED-O and Farms without any type of training $=$ NONTRAINED) on the farm handling variables. Farm positive behaviors (FPB), the speed and force used by the stockperson when restraining the animal with the head bail (REST.HB), and poor quality of subcutaneous injection (PQI).

\begin{tabular}{llll}
\hline Variable & TRAINED-R & TRAINED-O & NON-TRAINED \\
\hline FPB, actions/min & $7.43^{\mathrm{a}} \pm 0.19$ & $7.03^{\mathrm{ab}} \pm 0.19$ & $6.57^{\mathrm{b}} \pm 0.25$ \\
REST.HB, \% & $2.49^{\mathrm{c}} \pm 0.10$ & $3.20^{\mathrm{b}} \pm 0.07$ & $3.84^{\mathrm{a}} \pm 0.07$ \\
PQI, \% & $22.78^{\mathrm{b}} \pm 11.96$ & $48.25^{\mathrm{b}} \pm 11.85$ & $100.60^{\mathrm{a}} \pm 15.25$ \\
\hline
\end{tabular}

${ }^{\mathrm{a}-\mathrm{c}}$ Means followed by the same uppercase letters in the same row are not statistically different $(P>0.05)$ according to post-hoc Tukey tests.

For undesirable behaviors and accidents (UBA), we found a significant interaction between category of farm $\mathrm{x}$ animal breed-type $\left(\mathrm{F}_{4}\right.$, ${ }_{14}=10.48, P<0.01$ ), with higher UBA means for the crossbred adult males in the NON-TRAINED group, and lower UBA means for TRAINED-R Nellore cows and heifers, as shown in Table 5.

\subsection{Effect of the time elapsed within a workday on quality of handling and cattle behavior}

For the TRAINED-R and TRAINED-O farm groups, no significant effect $(P>0.05)$ of time passing (workday progression) was found on handling variables (FPB, FNB and UBA). However, for the NONTRAINED group, significant effects of farm group were found on FPB $\left(\mathrm{F}_{1}=9.06, P<0.01\right)$ and UBA $\left(\mathrm{F}_{1}=5.45, P<0.05\right)$, and a trend was
Table 5

Adjusted means ( \pm SE) of undesirable cattle behavior and accident (UBA, in numbers per farm) according to the farm training group (TRAINED-R, TRAINED-O and NON-TRAINED) and breed-type (Nellore calves, Nellore cows and heifers and crossbred adult males) interaction. Breed-type in columns and farm training group in rows.

\begin{tabular}{llll}
\hline $\begin{array}{l}\text { Training/animal } \\
\text { category }\end{array}$ & Nellore calves & $\begin{array}{l}\text { Nellore cows and } \\
\text { heifers }\end{array}$ & $\begin{array}{l}\text { Crossbred adult } \\
\text { males }\end{array}$ \\
\hline TRAINED-R & $4.15^{\mathrm{Bb}} \pm 0.14$ & $3.66^{\mathrm{Cb}} \pm 0.07$ & $5.16^{\mathrm{Ab}} \pm 0.06$ \\
TRAINED-O & $3.94^{\mathrm{Bb}} \pm 0.10$ & $3.85^{\mathrm{Bab}} \pm 0.09$ & $4.65^{\mathrm{Ac}} \pm 0.05$ \\
NON-TRAINED & $4.87^{\mathrm{Ba}} \pm 0.06$ & $4.02^{\mathrm{Ca}} \pm 0.09$ & $5.80^{\mathrm{Aa}} \pm 0.06$ \\
\hline
\end{tabular}

Means followed by the same uppercase letters $\left({ }^{\mathrm{A}-\mathrm{C}}\right)$ in the same row and same lower-case letters $\left({ }^{a-c}\right)$ in the same column are not statistically different $(P>0.05)$, according to post-hoc Tukey tests.

Table 6

Effect of time of handling within a day on stockpeople and cattle behavior for NON-TRAINED farm group: $\mathrm{Y}=\mathrm{a}+\mathrm{bx}+e_{\mathrm{x}}$, where $\mathrm{Y}$ is FPB (Farm positive behaviors, in actions/15 min), FNB (Farm negative behaviors, in actions/ $15 \mathrm{~min}$ ) and UBA (undesirable cattle behaviors and accidents, number/15 $\mathrm{min}$ ), $\mathrm{a}=$ intercept, $\mathrm{b}=$ regression slope, $\mathrm{x}=$ measured time (TIME, in min.) and $e_{\mathrm{x}}=$ error of prediction.

\begin{tabular}{llllll}
\hline Variables & $\mathrm{R}^{2}$ & Intercept & Regression slope & $\mathrm{SE}$ & $P$-value \\
\hline FPB & 0.133 & 4.402 & -0.059 & 0.019 & 0.004 \\
FNB & 0.056 & 4.610 & 0.037 & 0.019 & 0.065 \\
UBA & 0.098 & 2.736 & -0.081 & 0.035 & 0.024 \\
\hline
\end{tabular}

observed for FNB $\left(\mathrm{F}_{1}=3.52, P=0.065\right)$, showing that as time of handling passed within a day, stockpeople's positive behaviors, animals' undesirable behaviors and accidents decreased, while negative behaviors increased (Table 6).

\section{Discussion}

Stockperson attitudes and behaviors may be the most influential factor affecting animal handling, welfare and productivity (Coleman and Hemsworth, 2014). Thus, it is important to understand how to improve human-animal relationships during routine handling on beef cattle farms. Several stockpeople training programs have been developed in Brazil (Zuin et al., 2014), but no previous studies have investigated the impact of these programs on the quality of cattle handling and animal welfare. To our knowledge, this is the first study conducted in any country aiming to investigate the potential impact of different levels of access to information about good practices of beef cattle handling on stockpeople attitudes and quality of handling.

Overall, most stockpeople assessed in our study had higher agreement with the positive attitude questions and lower agreement with the negative attitude questions. Similar findings were reported by Boivin et al. (2007) in a study conducted with French cattle farmers. These results suggest that most beef stockpeople have adequate attitudes about cattle behavior and handling. However, it is not possible to interpret these scores in absolute terms, because the number of studies of this kind is very limited, and there are no standardized evaluation methods. Moreover, it is unknown to what extent slight variations in positive attitudes, for example, might affect behavior.

Nevertheless, our study reveals pertinent differences between the stockpeople training categories, indicating there is room for improvement. We found that stockpeople attitudes were associated with their access to handling skills training, suggesting that training programs of this nature can effectively improve stockpeople attitudes and behaviors. According to Grandin (2016), the factor that most affects quality of cattle handling is the attitudes of the management; indeed, our results show that stockpeople who participated in this formal training course had the highest positive and the lowest negative attitude scores. 
Hemsworth et al. (2002) reported that training based on cognitive-behavioral interventions improved stockpeople attitudes and reduced negative interactions with cows, and consequently, dairy cows' fear of humans. After a similar intervention in commercial pig farms, Coleman et al. (2000) found that training improved stockpeople's attitudes towards the animals.

In dairy and pig production, daily handling often occurs immediately following the training sessions. Practicing animal handling immediately and regularly after training allows stockpeople to experience the benefits of training every day, by observing the consequences of their behaviors on animals' reactions. Thus, attitudes toward the animal (in particular behavioral attitudes) could be improved by a feedback loop, since the nature and frequency of those behaviors determine the quality of human animal relationships. In turn, those relationships influence stockpeople attitudes and behaviors, thus affecting farm animal behavior, physiology and productivity (Hemsworth and Coleman, 2011). This is a common situation in dairy and pig production systems where humans and animals have close contact every day; however, such a situation usually does not occur in beef cattle production raised on pastures in Brazil, where cattle usually go to the corral only twice a year, for vaccination. Despite this difference, our results would suggest a possible positive impact of the handling skills training on stockpeople attitudes in beef cattle management as well. Nevertheless, we need to be careful with any conclusions, since our study was explorative, which highlights possible confounding factors. First, the presence of the observers could have affected the stockpeople's daily behavior; however, according to Xavier Boivin and Mateus Paranhos da Costa (personal communication), any changes would not last for the entire handling of many cattle, as this is a long, demanding working task. In addition, any effects would have been observed equally for all observed workers, since all stockpeople were evaluated by the same three observers. Second, according to our factor analysis results, higher positive and lower negative attitudes toward cattle were also associated with job satisfaction. It has been previously shown that job satisfaction and job performance are partly related (Judge et al., 2001). Finally, managing styles may have differed between farms with and without organized training sessions, making them dissimilar in aspects other than the training (e.g. human resources management, farm management practices, handling facilities, etc.) Thus, a better managing style within the farm that organized regular trainings could have favored the development of positive stockpeople attitudes towards the animals, or, alternatively, could have reinforced the beneficial effects of training.

Another important result of our study was that stockperson access to training and farm training category were related to more positive stockpeople behaviors. Indeed, it was expected that trained people would behave better towards cattle than those who did not receive any training or information about good cattle handling practices, in line with other studies conducted in the dairy cattle and pork industry (Hemsworth et al., 1994, 2002; Coleman et al., 2000). Interestingly, stockpeople who were not trained but worked on the same team and in direct contact with trained people also performed more positive behaviors towards cattle, suggesting a possible social facilitation, imitation or transfer of these types of behaviors. However, other mechanisms may also be evolved, as suggested by Kanekar (1976, p. 1): "attitudinal responses can be developed by conditioned emotional responses acquired through Pavlovian or classical conditioning". This means that humans can experience the emotions of others and, through the observation of reactions of other persons to a specific object or being (the animal, for example), others' actions may reinforce the subject to behave in a similar way (Kanekar, 1976; Hemsworth and Coleman, 2011). Furthermore, human behavior is a composition of four elements: "the action performed, the target at which the action is directed, the context in which it is performed, and the time at which it is performed" (Fishbein and Ajzen, 2010, p 29). Thus, the presence of someone who has been trained not only has the potential to change the normal context of animal handling on the farm, but also to affect the behavior of the non-trained people, possibly influencing them to behave more properly.

In relation to the other handling variables, at the NON-TRAINED farms we found a higher percentage of rough restraining of animals with head bail, and a poor quality of subcutaneous injections. Woiwode et al., (2016) reported a high rate of accidental improper capture with the head bail during routine handling of cattle in the corral, and suggested that improper capture may be related to the speed and force with which the animals enter the squeeze chute (which in turn may be determined by the animals' temperament), or to the experience or training level of the handler operating the chute. Animals' temperament is influenced by the way they are handled (Macedo et al., 2011; Rueda et al., 2015), and Non-trained people usually handled the animals in a way they learned over time through their cultural environment. According to Hemsworth et al. (2007), stockpeople normally may not appreciate that some handling practices are stressful and painful for the animals.

Previous studies investigating the relationship of stockpeople training with some handling practices, including head bail operation (Simon et al., 2016), revealed that the implementation of beef-quality improvement procedure training reduced the number of mis-catches with the head bail by $45 \%$. A Brazilian study investigating the quality of cattle vaccination showed that when people do not use good handling practices during vaccination procedures (e.g., vaccinating the animals in the wrong place or in a wrong way) the animals were more stressed, displayed more undesirable behaviors, and consequently suffered more welfare problems (Chiquitelli Neto et al., 2015). Indeed, our results also showed higher frequencies of undesirable animal behaviors (e.g., ESCAPE) and accidents for the crossbred adult males, especially on NONTRAINED farms. Lima et al. (2018) found that minor changes made in the corral, together with the adoption of good handling practices, reduced cattle agitation when animals were restrained in the squeeze chute. Moreover, Lyles and Calvo-Lorenzo (2014) reported that negative cattle handling leads to bad habits and dangerous behavior by cattle, elevating stress in both animals and stockpeople. This appears to confirm that human behavior affects animal behavior (Ellingsen et al., 2014), with negative consequences for animal welfare, due to the stressful situations that the animals may experience (Hemsworth et al., 1994). Animals learn to avoid conditioned stimuli associated with aversive events and, through this kind of learning (conditioning), their behavioral reactions may be regulated by the nature of previous experiences when interacting with humans (Hemsworth et al., 2002). Moreover, for adult cattle, previous specific interactions and their associated predictability during handling may influence their behavior (Waiblinger et al., 2006).

One important new result of our study is that handling deteriorated over time within a single day, but only on NON-TRAINED farms. It has been suggested that people who understand and apply the knowledge acquired in a training course about animal handling (including information about animal behavior) exhibit better handling, resulting in better animal behavior and lower stockpeople stress (Lindahl et al., 2013). When people do not know how best to handle animals, they could become more stressed, and consequently, their behavior could get worse (M.C. Ceballos, personal conversation with some stockpeople). Weakening attention, desensitization, weariness, but also irritability and poor judgment (Coetze and Klopper, 2010) might occur, which would explain the reduction of positive stockpeople behaviors and the increase in negative ones on the non-trained farms. It is also plausible that when people use negative behaviors (hitting, shouting, jumping, etc.) during handling, they feel more tired. Grandin (2015) suggests that tired people will abuse animals and that, in poultry and pig companies, animal injuries and death may double after the truck loading team works more than 6 hours. Our results are only explorative in this field and we need to develop new indicators of these dimensions for future studies. However, considering our present findings, we suggest 
that training stockpeople could help them be more conscientious for longer periods, despite the fatigue. There is also the alternative possibility that trained stockpeople feel less exhausted by the way they handle the animals, resulting in lower deterioration in their handling over time.

We recommend that beef cattle farmers invest in stockperson training, since such an intervention can improve animal handling. Future studies should make longitudinal analyses of stockpeople's attitudes and behaviors, as well as animals' responses to those behaviors, preferably by using electronic monitoring systems with cameras to avoid bias in human behavior. Another interesting future study could be to evaluate stockperson opinions about behavioral-cognitive training interventions in order to better understand the impact of such interventions on stockpeople's personal and professional lives.

\section{Conclusion}

As has been observed in research investigating explicit cognitivebehavioral training, the results of the current study (the first of its kind conducted with beef cattle) support the notion that training stockpeople on good practices of beef cattle handling is associated with better attitudes and behaviors towards animals. Furthermore, compared with untrained stockpeople, trained individuals maintained their good practices of handling over time. Good handling practices are associated with better animal behaviors, including lower reactivity and stress, not only because the animals behave better and are less prone to accidents, but also because they are handled with more positive behaviors by the stockpeople. In conclusion, training stockpeople is an effective and practical strategy to promote positive human-animal interactions on beef cattle farms and improve the quality of life of both animals and workers.

\section{Conflict of interest}

None.

\section{Acknowledgements}

We thank the managers and staff of all the farms included in our study. This research was funded by Fundo Vale - Pecuária Verde Project and Grupo de Estudos e Pesquisas em Etologia e Ecologia Animal (ETCO Group). We thank Professors Paul Hemsworth and Graham Coleman for their comments and editing help, which greatly improved the manuscript. The study was part of the PhD thesis of the manuscript's lead author in the Graduate Program in Animal Science at São Paulo State University (UNESP), Jaboticabal Campus, Brazil.

\section{References}

Boivin, X., Lensink, J., Tallet, C., Veissier, I., 2003. Stockmanship and farm animal welfare. Anim. Welf. 12, 479-492.

Boivin, X., Marcantognini, L., Boulesteix, P., Godet, J., Brulé, A., Veissier, I., 2007. Attitudes of farmers towards Limousin cattle and their handling. Anim. Welf. 16, 147-151.

Breuer, K., Hemsworth, P.H., Barnett, J.L., Matthews, L.R., Coleman, G.J., 2000. Behavioura response to humans and the productivity of commercial dairy cows. Appl. Anim. Behav. Sci. $66,273-288$.

Burnett, E.A., 2014. The Influence of Farmer Stress and Hardiness on Adoption of Best Management Practices in the Maumee Watershed (Electronic Thesis). Ohio State University 106. p. Retrieved from https://etd.ohiolink.edu/pg_10?0::NO:10:P10_ETD_SUBID:97356 (accessed 12 April 2017)

Chiquitelli Neto, M., Titto, C.G., Maia, A.S.C., Puoli Filho, J.N.P., Longo, A.L.S., Leme-dosSantos, T.D.C., Titto, E.A.L., Camerro, L.Z., Pereira, A.M.F., 2015. Rational management raises the Guzerat cattle welfare and improves the efficiency of vaccination work. J. Anim. Behav. Biomet. 3, 101-106.

Coetzee, S.K., Klopper, H.C., 2010. Compassion fatigue within nursing practice: a concept analysis. Nurs. Health. Sci. 12, 235-243.

Coleman, G.J., Hemsworth, P.H., Hay, M., Cox, M., 2000. Modifying stockperson attitudes and behaviour towards pigs at a large commercial farm. Appl. Anim. Behav. Sci. 66, 11-20.

Coleman, G.J., Hemsworth, P.H., 2014. Training to improve stockperson beliefs and behaviour towards livestock enhances welfare and productivity. Rev. Sci. Tech. Off. Int. Epiz. 33, $131-137$.
Douphrate, D.I., Stallones, L., Lunner Kolstrup, C., Nonnenmann, M.W., Pinzke, S., Hagevoort, G.R., Lundqvist, P., Jakob, M., Xiang, H., Xue, L., Jarvie, P., McCurdy, S.A., Reed, S., Lower, T., 2013. Work-related injuries and fatalities on dairy farm operations-a global perspective. J. Agromed. 18, 256-264.

Ellingsen, K., Coleman, G.J., Lund, V., Mejdell, C.M., 2014. Using qualitative behaviour assessment to explore the link between stockperson behaviour and dairy calf behaviour. Appl. Anim. Behav. Sci. 153, 10-17.

Fishbein, M., Ajzen, I., 2010. Predicting and Changing behavior: The reasoned Action Approach. Phychology Press, New York, USA.

Grandin, T., Deesing, M., 2008. Humane Livestock Handlin, first ed. Storey Publishing, North Adams, USA.

Grandin, T., 2015. The effect of economic factors on the welfare of livestock and poultry. In: Grandin, T (Ed.), Improving Animal Welfare: A Practical Approach, second ed. CABI International, Wallingford, UK.

Grandin, T., 2016. Evaluation of the welfare of cattle housed in outdoor feedlot pens. Vet. Anim. Sci. $1,23-28$.

Grandin, T., 2017. Recommended Animal Handling Guidelines \& Audit Guide (2005 Edition With 2007 and 2010 Updates). American Meat Institute, Washington, DC. USA. Available at http://animalhandling.org/sites/default/files/forms/animal-handling-guidelinesNov32017.pdf (accessed 10 April 2018).

Hemsworth, P.H., Coleman, G.J., Barnett, J.L., 1994. Improving the attitude and behaviour of stockpersons towards pigs and the consequences on the behaviour and reproductive performance of commercial pigs. Appl. Anim. Behav. Sci. 39, 349-362.

Hemsworth, P.H., Coleman, G.J., Barnett, J.L., Borg, S., Dowling, S., 2002. The effects of cognitive behavioral intervention on the attitude and behavior of stockpersons and the behavior and productivity of commercial dairy cows. J. Anim. Sci. 80, 68-78.

Hemsworth, P.H., 2007. Ethical stockmanship. Aust. Vet. J. 85, 194-200.

Hemsworth, P.H., Coleman, G.J., 2011. Human-livestock interactions: The stockperson and the Productivity of Intensively Farmed Animals, second ed. CABI International, Wallingford, UK.

IBGE (Instituto Brasileiro de Geografia e Estatística), 2016. Produção da Pecuária Municipal 2015. Ministério do Planejamento. Orçamento e Gestão / Instituto Brasileiro de Geografia e Estatística: Rio de Janeiro 43, 49. Available at http://biblioteca.ibge.gov.br/visualizacao/ periodicos/84/ppm 2015 v43 br.pdf (accessed 11 March 2017).

Judge, T.A., Thoresen, C.J., Bono, J.E., Patton, G.K., 2001. The job satisfaction-job performance relationship: a qualitative and quantitative review. Psychol. Bull. 127, 376-407.

Kanekar, S., 1976. Observational learning of attitudes: a behavioral analysis. Eur. J. Soc. Psychol. 6, 1-24.

Lindahl, C., Lundqvist, P., Hagevoort, G.R., Lunner Kolstrup, C., Douphrate, D.I., Pinzke, S., Grandin, T., 2013. Occupational health and safety aspects of animal handling in dairy production. J. Agromed. 18, 274-283.

Lima, M.L.P., Negrão, J.A., de Paz, C.C.P., Grandin, T., 2018. Minor corral changes and adoption of good handling practices can improve the behavior and reduce cortisol release in Nellore cows. Trop. Anim. Health Prod. 50, 525-530.

Lyles, J.L., Calvo-Lorenzo, M.S., 2014. Practical developments in managing animal welfare in beef cattle: what does the future hold? J. Anim. Sci. 92, 5334-5344.

Macedo, G.G., Zúccari, C.E.S.N., de Abreu, U.G.P., Negrão, J.A., da Costa e Silva, E.V., 2011. Human-animal interaction, stress, and embryo production in Bos indicus embryo donors under tropical conditions. Trop. Anim. Health Prod. 43, 1175-1182.

Martin, P., Bateson, P., 2007. Measuring behaviour: An introductory Guide, third ed. Cambridge University, Cambridge.

Menger, L.M., Pezzutti, F., Tellechea, T., Stallones, L., Rosecrance, J., Roman-Muniz, I.N., 2016. Perceptions of health and safety among immigrant Latino/a dairy workers in the US. Front. Pub. Health. 4, 1-13.

National Institute for Occupational Safety and Health, NIOSH, 1999. STRESS... at work. DHHS (NIOSH) Publication Number 99-101, 32 p. Cincinnati, OH: National Institute for Occupational Safety and Health. Available at https://www.cdc.gov/niosh/docs/99-101/ pdfs/99-101.pdf (accessed 25 April 2018).

Paranhos da Costa, M.J.R., Toledo, L.M., Schmidek, A., 2006. Boas Práticas no Manejo: Vacinação. 1 $1^{a}$ edição. Editora Funep, Jaboticabal-SP, 28 p. Available at http://www. grupoetco.org.br/arquivos br/manuais/manual-boas-praticas-de-manejo vacinacao. pdf (accessed 20 September 2017).

Probst, J.K., Neff, A.S., Leiber, F., Kreuzer, M., Hillmann, E., 2012. Gentle touching in early life reduces avoidance distance and slaughter stress in beef cattle. Appl. Anim. Behav. Sci. 139, $42-49$.

Rueda, P.M., Sant'Anna, A.C., Valente, T.S., Paranhos da Costa, M.J.P., 2015. Impact of the temperament of Nellore cows on the quality of handling and pregnancy rates in fixed-time artificial insemination. Livest Sci. 177, 189-195.

Schmied, C., Boivin, X., Scala, S., Waiblinger, S., 2010. Effect of previous stroking on reactions to a veterinary procedure Behaviour and heart rate of dairy cows. Interact. Stud. 11, 467-481.

Simon, G.E., Hoar, B.R., Tucker, C.B., 2016. Assessing cow-calf welfare. Part 2: Risk factors for beef cow health and behavior and stockperson handling. J. Anima. Sci. 94, 3488-3500.

USDA (United States Department of Agriculture, 2018. Livestock and poultry: world markets and trade. Foreign Agric. Serv. 30. p. Available at https://apps.fas.usda.gov/psdonline/ circulars/livestock_poultry.pdf > . (accessed 19 June 2017).

Waiblinger, S., Menke, C., Coleman, G., 2002. The relationship between attitudes, personal characteristics and behaviour of stockpeople and subsequent behaviour and production of dairy cows. Appl. Anim. Behav. Sci. 79, 195-219.

Waiblinger, S., Boivin, X., Pedersen, V., Tosi, M.V., Janczak, A.M., Visser, E.K., Jones, R.B., 2006. Assessing the human-animal relationship in farmed species: a critical review. Appl. Anim. Behav. Sci. 101, 185-242.

Woiwode, R., Grandin, T., Kirch, B., Paterson, J., 2016. Effects of initial handling practices on behavior and average daily gain of fed steers. Int. J. Livest. Prod. 7, 12-18.

Zuin, L.F.S., Zuin, P.B., Monzon, A.G., Paranhos da Costa, M.J.R., Oliveira, I.R., 2014. The multiple perspectives in a dialogical continued education course on animal welfare: accounts of a team of extension agents and a manager and a cowboy from a rural Brazilian territory. Linguist. Educ. 28, 17-27. 